\title{
The Effect of Visit Exhibition Experience and Virtual Exhibition Experience on Experience Satisfaction and Purchase Intention
}

\author{
Seung-Wan Ju \\ Department of Business Administration, Tongmyong University, Busan, Korea \\ gauace@naver.com
}

\begin{abstract}
This study is aimed to examine how the experience of visiting exhibition and virtual exhibition have an effect on experience satisfaction and purchase intention in order to suggest effective direction and development direction of corporate public relations exhibition hall. Through the examination, this study also aims to find out the way to secure potential customers and to raise corporate image and purchase behavior through the experience of exhibition hall for corporate public relations, which not only provides cultural services through advanced exhibition presentation techniques but also contributes to regional cultural development by offering cultural space. Therefore, this study empirically analyzed the effects of exhibition experience of corporate public relations exhibition hall on consumer purchase intention for visitors who have experienced domestic corporate public relations exhibition hall and virtual exhibition experience. Based on the results of the empirical analysis, the corporate promotion exhibition hall needs to develop exhibition presentations focusing more on aesthetic elements in experiential exhibition presentations in order to inspire the exhibition effect of visiting exhibition experiences. Also, for the exhibition effect of virtual exhibition experience, it is necessary to actively develop hardware and software focusing on accessibility and convenience of applications and homepage. Through this, the corporate public relations exhibition hall will be able to bring about the effect of communicating with customers, promoting products and promoting corporate image.
\end{abstract}

Keywords: Corporate promotion, Exhibition hall, Exhibition experience, Experience satisfaction, Purchase intention

\section{Introduction}

In order to show they ways of display and development of the hall, this study suggests that the corporate exhibition hall should be developed into the space satisfying customer's various demands through the increase of familiarity and communication between customers and business not only by examining how much influence the exhibition experience have on customers' satisfaction and purchase intention but also by presenting some improvements and future direction of display design. Also, the study aims to find ways to secure potential customers, enhance corporate image, and induce purchasing behavior through corporate promotion exhibition halls by providing cultural services through advanced exhibition presentation techniques and providing local cultural spaces contributing to regional cultural development to consumers and future potential customers.

Article history:

Received (December14, 2020), Review Result (January 19, 2021), Accepted (January 4, 2021) 


\section{Theoretical Background}

The term corporate promotion exhibition hall is a term typically included or used in the scope of the corporate museum whose operating subjects are business entities. According to the classification prescribed by the Museum Act, the corporate museum belongs to the science museum, the industrial technology museum, the history museum or the folk museum, which is a specialized museum specializing in detailed collections.[1]

Until the 1990s, most of the permanent exhibition halls in Korea were established in the form of showrooms to promote corporate products and technology.[2] At that time, there were two purposes that companies established the exhibition hall: honoring the virtues of corporate founders establishing a corporate publicity center as part of promoting the government's economic growth policy at the time.[3] Following this periodic environment, the boom of the world economy and the continuous economic growth of domestic companies have increased the leisure time of the people, which has become the reason why the people themselves are interested in improving the cultural level. With education for the public increasingly emphasized, specialized exhibition halls for the development and education of cultural thinking have begun to emerge.[4]

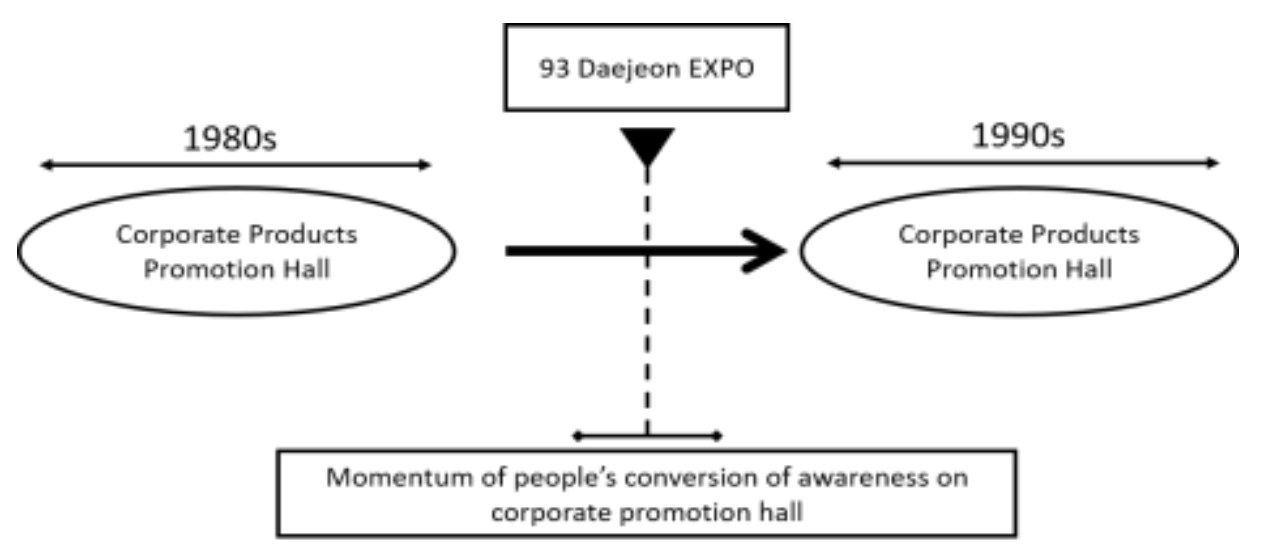

Figure 1. The conceptual change of Korean corporate promotion exhibition hall [5]

Visit exhibitions can be defined as seeing things such as artistic personal works, joint exhibitions, performance works, formative arts and visual arts in real space by paying a certain amount of money.[6] On the other hand, virtual exhibition refers to exhibitions in computer virtual space, which is a kind of communication that delivers information to be displayed by interacting with users based on online network technology.[7]

Experience is a collective term for all the psychology that occurs in the facts or experiences we have experienced directly, the resulting knowledge and function, the contents that are realized by the sense or perception of the objective object, and the actions that accompany it. The experience in exhibition can be defined as being conveyed or understood and recognized through direct and indirect participation or action of the viewer.[8]

In the dictionary sense, satisfaction is defined as a state of liking or satisfaction without shortage. In addition, satisfaction has been defined by many scholars in business administration and tourism for a long time, and especially in tourism, there has been a good deal of research on satisfaction.[9] 
Purchase intention is the will and belief of the individual that appears as future behavior after consumers form an attitude toward a state, and the purchase intention is defined as the rational judgment dimension of the individual.[10] In addition, given the psychological aspect, purchase intention is a psychological attitude derived from the purchase intention of the consumer as a comprehensive evaluation of the brand such as desire to purchase, recommendation intention, availability, and priority consideration.

Table 1. The difference between visit exhibition and virtual exhibition [11]

\begin{tabular}{|c|c|c|}
\hline Item & Visit Exhibition & Virtual Exhibition \\
\hline Purpose & $\begin{array}{l}\text { To enhance visual efficiency of exhibits } \\
\text { and to construct environment for } \\
\text { protection. }\end{array}$ & $\begin{array}{l}\text { To convey information about the exhibition } \\
\text { object and create culture through low poetry. }\end{array}$ \\
\hline $\begin{array}{l}\text { Knowledge } \\
\text { required }\end{array}$ & $\begin{array}{l}\text { Architecture, materials, and mechanics as } \\
\text { well as aesthetic design skills }\end{array}$ & $\begin{array}{l}\text { A broad knowledge of aesthetic design skills, } \\
\text { networking skills with multi-media }\end{array}$ \\
\hline $\begin{array}{l}\text { Object of } \\
\text { exhibition }\end{array}$ & Material and Realistic object & $\begin{array}{c}\text { Relatively less constraints on the display } \\
\text { object }\end{array}$ \\
\hline Display space & $\begin{array}{l}\text { Generally, it is made in physical buildings } \\
\text { such as museums, art galleries, and } \\
\text { professional exhibition halls. }\end{array}$ & $\begin{array}{c}\text { Computers through digital media such as CD- } \\
\text { ROM, WWW, KIOSK are the bases of } \\
\text { exhibition. }\end{array}$ \\
\hline $\begin{array}{l}\text { Exhibition } \\
\text { technique }\end{array}$ & $\begin{array}{c}\text { The visual technique of the exhibition } \\
\text { object and the exhibition environment } \\
\text { naturally induces the viewer }\end{array}$ & $\begin{array}{l}\text { The use of multimedia means the interaction } \\
\text { between objects of exhibition, exhibition } \\
\text { space, and audience through various media }\end{array}$ \\
\hline $\begin{array}{l}\text { Exhibition } \\
\text { period }\end{array}$ & $\begin{array}{c}\text { It can be classified as a permanent } \\
\text { exhibition and a special exhibition. } \\
\text { Viewers are allowed only for a certain } \\
\text { time }\end{array}$ & $\begin{array}{c}\text { Exhibition is possible without being affected } \\
\text { by the time after production according to the } \\
\text { intention of the exhibitor }\end{array}$ \\
\hline
\end{tabular}

\section{Research Design}

In order to empirically show the flow of the study, a research model such as [Figure 2] was set up to compare and review the influence of independent variables such as visit exhibition experience and virtual exhibition experience on experience satisfaction and purchase intention, respectively, based on literature and previous studies

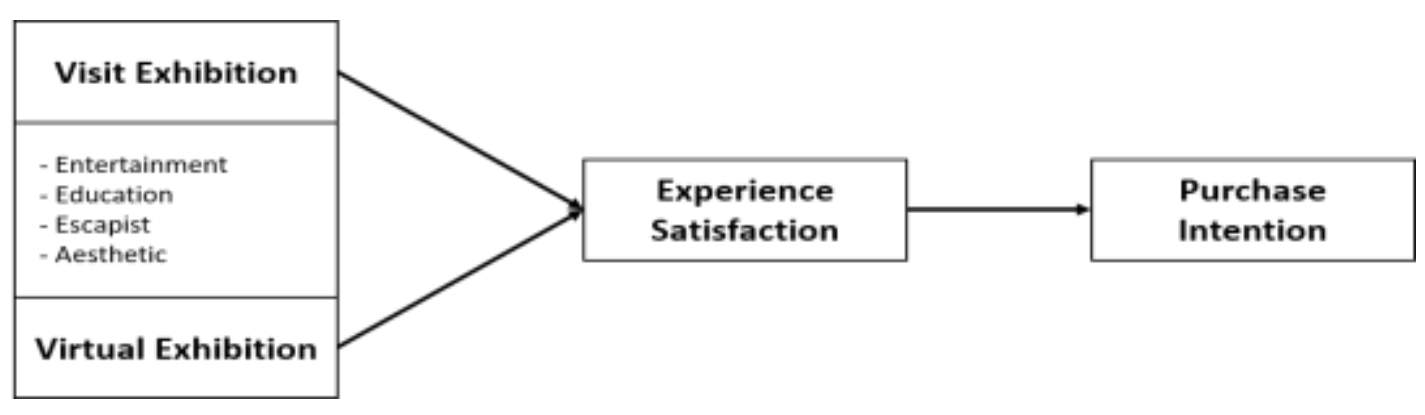

Figure 2. Research model

In addition, this study establishes the following hypotheses and further sets up subhypotheses in accordance to elements of each variable based on the statement that the 
experience of visiting exhibition and virtual exhibition of corporate public relations exhibition hall will have a significant effect on experience satisfaction and purchase intention respectively.

Hypothesis 1 Visit exhibition experience will have a significant influence on experience satisfaction.

H1-1 The entertainment experience of the visiting exhibition experience will have a significant influence on the experience satisfaction.

H1-2 The educational experience of visiting exhibition experience will have a significant effect on experience satisfaction.

H1-3 The deviant experience from the visiting exhibition experience will have a significant effect on the experience satisfaction.

H1-4 The aesthetic experience of visiting exhibition experience will have a significant effect on experience satisfaction.

Hypothesis 2 Virtual exhibition experience will have a significant influence on experience satisfaction.

H2-1 The entertainment experience of the virtual exhibition experience will have a significant influence on the experience satisfaction.

$\mathrm{H} 2-2$ The educational experience of virtual exhibition experience will have a significant effect on experience satisfaction.

H2-3 The deviant experience from the virtual exhibition experience will have a significant effect on the experience satisfaction.

H2-4 The aesthetic experience of virtual exhibition experience will have a significant effect on experience satisfaction

Hypothesis 3 Visit exhibition experience will have a significant influence on purchase intention.

Hypothesis 4 Virtual exhibition experience will have a significant influence on purchase intention.

\section{Empirical analysis}

\subsection{Validity and reliability}

Author names and affiliations are to be centered beneath the title and printed in Times New. In this study, exploratory factor analysis was conducted as a method of validity analysis, and KMO sample suitability measurement and Bartlett's sphere formation test were conducted to evaluate whether the measured value is suitable for factor analysis. In addition, in order to simplify the structure of the main component analysis factors, Varimax rotation method was used and eigenvalue of only one or more factors was extracted. The commonness analysis was conducted by extracting factors repeatedly by excluding items below .50 , and reliability analysis was conducted by evaluating the internal consistency of the measurement value, and the judgment criteria were Chonbach's $\alpha>.70$. KMO measure of visit experience was .727, Bartlett's test value was 4007.358 , and significance probability was .0000 , which was suitable for factor analysis by rejecting null hypothesis. The reliability criterion Chonbach's value was 0.900 for entertainment experience, 0.865 for educational experience, and 0 for deviating experience. Escapist experience was 0.736 and aesthetic experience was 0.736 , which was higher than 0.7, the standard value of internal consistency evaluation, showing that there is internal consistency. In addition, KMO measure of experience satisfaction and purchase intention of visit experience was .854, Bartlett's test value was 2281.379, and significance probability was .000 , which was appropriate for factor analysis by rejecting null hypothesis. 
Chonbach's index was .817 , purchase intention .945 showed that there was internal consistency. KMO measurement of virtual exhibition experience was .730, Bartlett's test value of sphere formation was 3450.691 , and significance probability was .000 , which was suitable for factor analysis by rejecting null hypothesis. The result of reliability analysis was 0.908 for educational experience, 0.878 for deviating experience, 0.814 for entertainment experience, and 0.878 for escapist experience. The aesthetic experience was 0.784 , showing that there was internal consistency. In addition, KMO measure of experience satisfaction and purchase intention of virtual exhibition experience was .702, Bartlett's test value of sphere formation was 2073.613, and significance probability was .000 , which was appropriate for factor analysis by rejecting null hypothesis. The result of analyzing reliability of experience satisfaction and purchase intention was 0.887 for purchase intention and 0.887 for experience satisfaction 0.821 , showing that there was internal consistency.

\subsection{Hypothesis test}

Examined in details of the test result of hypothesis 1, the non-standardization coefficient of entertainment experience was 0.271 , the non-standardization coefficient of educational experience was 0.162 in the relationship between educational experience and experience satisfaction, and the non-standardization coefficient of deviant experience was 0.358 in the relationship between escapist experience and experience satisfaction. In the significance level $\mathrm{p}<0.001$, three factors out of four sub-factors were statistically significant. However, because it was shown that the relationship between aesthetic experience and experience satisfaction was not statistically significant, hypothesis 1 was partially supported. In summary, entertainment experience, educational experience and escapist experience were found to increase experience satisfaction in visit exhibition experience, and aesthetic experience did not affect the increase of experience satisfaction, so it is judged that strong aesthetic elements such as color and lighting is necessary in designing the exhibition experience.

If the test result of hypothesis 2 is examined in details, the non-standardization coefficient of entertainment experience for experience satisfaction was 0.123 , the non-standardization coefficient of educational experience for experience satisfaction was 0.239 , and the nonstandardization coefficient of deviant experience for experience satisfaction was 0.262 , and the relationship between aesthetic experience and experience satisfaction was 0.262 . The nonstandardization coefficient of aesthetic experience for experience satisfaction was 0.272 . So, all four sub-factors were statistically significant at the significance level $\mathrm{p}<0.001$. Therefore, hypothesis 2 is supported. In summary, all factors of the experience of virtual exhibition, educational experience, escapist experience and aesthetic experience increase the satisfaction of experience, suggesting that the experience of virtual exhibition is an efficient experience.

Hypothesis 3 being examined in details as shown in [Table 8], the non-standardization coefficient of experience satisfaction for purchase intention was 1.011, which was statistically significant at the significance level $\mathrm{p}<0.001$. Therefore, after the experience of the exhibition, the satisfaction of the experience had a positive effect on the purchase intention. So, hypothesis 3 was supported. In summary, the entertainment experience, educational experience and escapist experience in the relationship between visit exhibition experience and experience satisfaction increased experience satisfaction. So, it can be said that experience satisfaction had a positive effect on purchase intention.

Hypothesis 4 being examined in details as shown in [Table 9], the non-standardization coefficient of experience satisfaction for purchase intention was .350, which was statistically significant at the significance level $\mathrm{p}<0.001$. After the virtual exhibition experience, the 
experience satisfaction had a positive effect on the purchase intention. Therefore, hypothesis 4 was supported. In summary, in the relationship of the virtual exhibition experience and experience satisfaction, the entertainment experience, the educational experience, the escapist experience and the aesthetic experience increased the experience satisfaction, which positively influenced the purchase intention. So, it can be said that the higher the 4 factors, the higher purchase intention.

\section{Conclusions}

This study aims not only to identify the effects of the company's promotion exhibition experience and virtual exhibition experience on the experience satisfaction and purchase intention, but also to suggest the future direction of the company's promotion exhibition hall by comparing the results. By applying 4 experience factors-entertainment experience, educational experience, deviating experience, aesthetic experience- proposed by Pine \& Gilmore, the results of empirical analysis and analysis can be summarized as follows as a way of understanding the effect of the experience of the company's promotion exhibition hall and the experience of virtual exhibition on the satisfaction of experience and purchase intention.

First, among the four sub-factors of the experience of visit exhibition, three factors of entertainment experience, educational experience, and escapist experience were verified to have a significant effect on the satisfaction of experience. The implication of the empirical analysis is that the corporate promotion exhibition hall should pay more attention to design, color, and lighting, which are aesthetic factors in the current experiential exhibition production form, in order to increase the experience satisfaction of visitors and to lead to corporate image, brand value and positive word-of-mouth behavior.

Second, in the relationship between the experience of visit exhibition and the satisfaction of experience, the experience of entertainment, educational experience and escapist experience increased the satisfaction of experience, and the satisfaction of experience had a positive effect on the purchase intention. Therefore, it can be said that the higher the degrees of above three factors, the higher the purchase intention.

Third, as a result of the relationship between virtual exhibition experience and experience satisfaction, all four factors of entertainment experience, educational experience, escapist experience, and aesthetic experience in online exhibition experience were analyzed to have a significant relationship with experience satisfaction.

Fourth, as a result of the relationship between experience satisfaction and purchase intention after virtual exhibition experience, experience satisfaction was found to have a significant relationship with purchase intention. This means that the higher the satisfaction of experience, the higher the purchase intention.

The academic implication of this study lies in having revealed the relation between the experience satisfaction and purchase intention by empirically analyzing the relationship of experience satisfaction and purchase intention from the visit experience and virtual experience in corporate promotion exhibition hall.

In the follow-up study, it is necessary to carry out research on contact points including various variables such as information desk and guide method other than four above experiential factors in order to provide the best experience to consumers visiting corporate promotion hall. If the research is conducted on local small and medium-sized enterprises besides the corporate promotion exhibition halls of large corporations, it will have its own meaning.

\section{References}


[1] J. S. Hyeong, "Structure of exhibition scenario and space arrangement programming in the enterprise museum," M.S. thesis, Seong-Gyun-Gwna University, Seoul, pp.4 (2002)

[2] B. H. Ryu and Y. S Moon, "A role of corporate museum: In case of a more-pacific museum of art," Journal of Arts and Cultural Management, vol.4, no.2, pp.23-40, (2011)

[3] J. W. Sung, B. S. Kim and J. Y. Lee, "A study on the effects of firm's internal characteristics on exhibition and market performance," International Journal of Trade Fairs and Exhibition Studies, vol.15, no.5, pp.101-125, (2020)

[4] G. M. Chae, "A study on the changing conception of enterprise showroom in Korea," Arts and Physical Education Journal, vol.8, pp.189-200, (1997)

[5] T. H. Noh, "A study on the corporate promotional space of experiential marketing," M.S thesis, Gun-Kuk University, pp.39, (2012)

[6] Y. H. Yoon, M. S. Kim and Y. S. Yoon, "The effects of exhibition experience elements(4Es) on B2C exhibition visitors' satisfaction and behavior intention - Focused on visitors of 'Korea character licensing fair 2019'," International Journal of Trade Fairs and Exhibition Studies, vol.15, no.2, pp.21-41, (2020)

[7] J. Y. Yuk, “A study on the web-based online exhibition,” M.S thesis, Hong-Ik University, Seoul, pp.4 (2019)

[8] H. J. Kwak, "A study on display of museum exhibition for synesthetic experience," M.S thesis, Hong-Ik University, Seoul, pp.8, (2007)

[9] K. H. Min, "Study on the impacts of tourists' landmark recognition factors on tourist attraction image and tourist satisfaction, behavioral intention," International Journal of Tourism Sciences, vol.29, no.3, pp.21-40, (2014)

[10] J. A. Jeon, "A study on brand equity's influence on tile consumer purchase intention of user's tastes: With focus on the hotel braw bakery," Tourism and Leisure Research, vol.20, no.3, pp.227-247, (2008)

[11] S. J. Chung and S. Y. Kim, "Analysis of user experience of virtual exhibitions," Journal of Basic Design and Art, vol.21, no.3, pp.329-340, (2020) 
The Effect of Visit Exhibition Experience and Virtual Exhibition Experience on Experience Satisfaction and Purchase Intention

This page is empty by intention. 